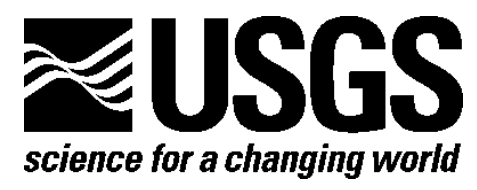

\title{
Gravity Data from the San Pedro River Basin, Cochise County, Arizona
}

By Jeffrey R. Kennedy and Daniel Winester

Open-File Report 2011-1287

U.S. Department of the Interior

U.S. Geological Survey 


\section{U.S. Department of the Interior \\ KEN SALAZAR, Secretary}

\section{U.S. Geological Survey \\ Marcia K. McNutt, Director}

U.S. Geological Survey, Reston, Virginia 2011

For product and ordering information:

World Wide Web: http://www.usgs.gov/pubprod

Telephone: 1-888-ASK-USGS

For more information on the USGS-the Federal source for science about the Earth, its natural and living resources, natural hazards, and the environment:

World Wide Web: http://www.usgs.gov

Telephone: 1-888-ASK-USGS

Suggested citation:

Kennedy, J.R., Winester, D., 2011, Gravity data from the San Pedro River Basin, Cochise County, Arizona: U.S. Geological Survey Open-File Report 2011-1287, 11 p. and data files, available at http://pubs.usgs.gov/of/2011/1287/.

Any use of trade, product, or firm names is for descriptive purposes only and does not imply endorsement by the U.S. Government.

Although this report is in the public domain, permission must be secured from the individual copyright owners to reproduce any copyrighted material contained within this report. 


\section{Contents}

Abstract

\section{Appendixes}

1. Gravity, free-air anomaly, simple Bouguer anomaly, and complete Bouguer anomaly values (http://pubs.usgs.gov/of/2011/1287/of2011-1287_appendixes)

2. Gravity differences over time in the Upper San Pedro Basin (http://pubs.usgs.gov/of/2011/1287/of2011-1287_appendixes)

3. Absolute gravity measurements (http://pubs.usgs.gov/of/2011/1287/of2011-1287_appendixes)

4. Site descriptions for absolute gravity stations and their excenters located near Benson,

Palominas, and Tombstone (http://pubs.usgs.gov/of/2011/1287/of2011-1287_appendixes/of2011-1287_appendix4.pdf).

\section{Figures}

1. Map of the study area showing location of gravity stations presented in appendices, Upper San Pedro River Basin, Arizona.

2. Method used to calculate gravity differences and standard deviation from repeat observations. (M., measurement; Diff., gravity difference)

3. Map of the southern part of the study area showing GPS stations occupied in 2002 and 2009 .

\section{Table}

1. Global Positioning System (GPS) derived ellipsoid heights for selected gravity stations, San Pedro River Basin, Arizona. [Accuracy reported at 95 percent confidence level; height is relative to GRS80 ellipsoid; NA, GPS data not available for this station; --, station height fixed during network adjustment] 


\section{Conversion Factors}

\begin{tabular}{lll}
\hline \multicolumn{1}{c}{ Multiply } & By & \multicolumn{1}{c}{ To obtain } \\
\hline centimeter $(\mathrm{cm})$ & Length & \\
meter $(\mathrm{m})$ & 0.3937 & inch (in.) \\
kilometer $(\mathrm{km})$ & 3.281 & foot $(\mathrm{ft})$ \\
meter $(\mathrm{m})$ & 0.6214 & mile $(\mathrm{mi})$ \\
\hline & 1.094 & yard $(\mathrm{yd})$ \\
\hline microGal $(\mu \mathrm{Gal})$ & Acceleration & \\
microGal $(\mu \mathrm{Gal})$ & 10 & nanometer $/ \mathrm{second}^{2}\left(\mathrm{~nm} / \mathrm{s}^{2}\right)$ \\
\hline
\end{tabular}




\title{
Gravity Data from the San Pedro River Basin, Cochise County, Arizona
}

\author{
By Jeffrey Kennedy, U.S. Geological Survey, and Daniel Winester, National Geodetic Survey
}

\begin{abstract}
The U.S. Geological Survey, Arizona Water Science Center in cooperation with the National Oceanic and Atmospheric Administration, National Geodetic Survey has collected relative and absolute gravity data at 321 stations in the San Pedro River Basin of southeastern Arizona since 2000. Data are of three types: observed gravity values and associated free-air, simple Bouguer, and complete Bouguer anomaly values, useful for subsurface-density modeling; high-precision relative-gravity surveys repeated over time, useful for aquifer-storage-change monitoring; and absolute-gravity values, useful as base stations for relative-gravity surveys and for monitoring gravity change over time. The data are compiled, without interpretation, in three spreadsheet files. Gravity values, GPS locations, and driving directions for absolute-gravity base stations are presented as National Geodetic Survey site descriptions.
\end{abstract}

\section{Introduction}

Gravity data have been collected using relative and absolute gravimeters at 321 stations in the San Pedro Basin in southeast Arizona for use in subsurface density modeling and monitoring of aquifer storage change over time. In the Benson Subwatershed part of the basin, data were collected at 272 stations for use in a subsurface density model. Six individual absolute-gravimeter stations, measured biannually, also have been established in this area for the purpose of monitoring aquifer-storage change, with the earliest starting in 2000. A 45-station network in the Sierra Vista Subwatershed part of the basin has been surveyed biannually, starting in 2005 , for the purpose of monitoring aquifer-storage change. Redundant relative-gravimeter measurements tied to absolute-gravimeter measurements in this area provide well-constrained gravity-change data. GPS observations at or near most stations provide precise positioning and elevation control.

\section{Acknowledgments}

Many individuals have contributed to the data presented. Bruce Gungle, Donald Pool, David Schmerge, John Fleming, Carl Anderson, Emmet McGuire, and Nate Blomgren have all contributed to relative-gravity surveys. Paul Gettings, Felipe Caldeira, and Kyle Withers collected GPS data. Robert Carruth has provided valuable assistance in collecting A10 data, as has Roy Anderson with FG5 surveys. Fort Huachuca (U.S. Army), Agricultural Research Service, Palominas Fire District, Kartchner Caverns State Park, and many private landowners have generously provided access to gravity stations. 


\section{Gravity and Anomaly Values}

Gravity data (appendix 1) are derived from three sources. First, relative-gravity observations at 272 sites (fig. 1) were collected by the U.S. Geological Survey (USGS) in the Benson Subwatershed in 2005 and 2006 using LaCoste and Romberg D-209 and D-127 meters equipped with analog feedback and Aliod nulling systems, respectively. These systems allow for increased accuracy by nulling the beam by means of an electronic feedback mechanism, displaying the gravity value on an LCD display rather than requiring reading through the eye piece. Gravity measurements were made relative to an absolute-gravity excenter (BENSON CA) established by the National Geodetic Survey (NGS) at Kartchner Caverns State Park and a secondary base station established by USGS with an A10 absolute gravimeter near the intersection of Interstate 10 and State Highway 90. The purpose of this data collection was to develop a hydrogeologic framework for the Benson Subwatershed (Dickinson and others, 2010). Observations were first corrected for earth-tide variation using the Berger tide model (Micro-g LaCoste, Inc., 2001), followed by correction for meter drift by repeatedly occupying a common base station and assuming a linear drift rate. One hundred forty of these stations were located using post-processed differential GPS, with an average ellipsoid height accuracy of $0.67 \mathrm{~m}$. The remaining stations were positioned using autonomous GPS, with a nominal ellipsoid height accuracy of about $10 \mathrm{~m}$. However, when autonomous GPS elevations are compared to elevations obtained from a 10 $\mathrm{m}$ digital elevation model (DEM) of the region, the mean absolute error is $2.54 \mathrm{~m}$.

Relative-gravity observations collected for aquifer storage-change monitoring at 45 sites in the Upper San Pedro Basin, primarily using a LaCoste and Romberg relative gravimeter (D-209), are the second source of gravity data (appendix 2). These observations are made relative to three of the absolute gravimeter stations (or their excenters) established by NGS (FT. HUACHUCA AA, TOMBSTONE AA, PALOMINAS AA) (fig. 1). A single gravity value for each station is determined from a least-squares network adjustment of the December 2009 survey. Vertical positions for most stations are determined with about $\pm 2 \mathrm{~cm}$ accuracy from differential GPS surveys. Further details about gravity observations over time are presented in the next section.

Observations at 26 sites (appendix 3) made using Micro-g LaCoste, Inc., portable free-fall absolute gravimeters (numbers FG5-102 and A10-008; FG5-102 was originally manufactured by Axis Instruments, Inc.) are the third source of gravity data. These meters directly measure the acceleration of a test mass falling in a vacuum as tracked by laser interferometry. Corrections are applied for earth tides, ocean loading, polar motion, and barometric pressure. For the FG5, the gravity value at the instrument height $(131 \mathrm{~cm})$ is transferred to the land surface using a vertical gradient measured with LaCoste and Romberg D-17 and D-43 relative gravimeters equipped with analog feedback nulling systems. At A10 sites, the gravity value at the land surface is estimated by subtracting the instrument height $(71.7 \mathrm{~cm})$ multiplied by the free-air gradient $(-3.086 \mu \mathrm{Gal} / \mathrm{cm})$, or $-221 \mu \mathrm{Gal}$, from the measured gravity value. Further details about absolute gravity observations are presented in the "Absolute Gravity Measurements" section.

Each FG5 site has an associated absolute excenter, an outdoor station which provides an accessible monument for GPS and relative-gravity surveys. Gravity values at excenters are determined by using the same LaCoste and Romberg relative gravimeters used in gradient measurements. The excenters were located using GPS (with NGS OPUS solutions) while the FG5 operated simultaneously indoors. These absolute gravimeter sites and excenters are FT. HUACHUCA AA (absolute), FT. HUACHUCA 1570 (also known as ASA1570, excenter and later A10 site), BENSON AA (absolute), BENSON CA (excenter), PALOMINAS AA (absolute), PALOMINAS DA (excenter), TOMBSTONE AA (absolute), TOMBSTONE CA (excenter), and TOMBSTONE DA (second excenter and later A10 
site). As of fall 2011, ASA1570 has been destroyed and access at FT. HUACHUCA AA is restricted. Time-averaged gravity values for the other stations are reported on the site descriptions (appendix 4).

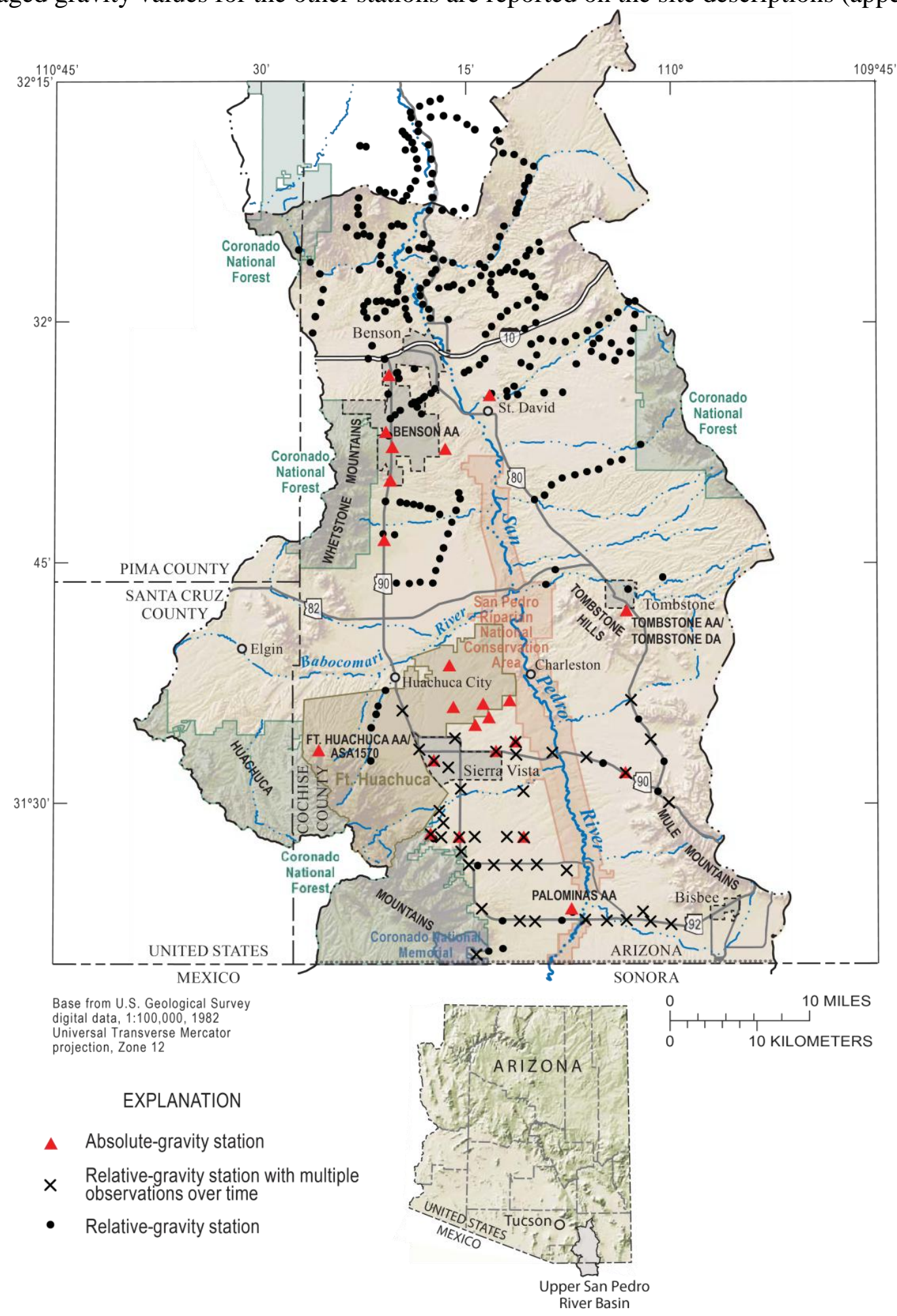

Figure 1. Map of the study area showing location of gravity stations presented in appendices, Upper San Pedro River Basin, Arizona. 
Formulae used to derive gravity anomalies are consistent with established standards (Hinze and others, 2005, equations 2, 5, 6, and 7). Theoretical gravity on the ellipsoid was determined by using the 1980 International Gravity Formula (IGF) in the Somigliana closed form, and the free-air correction was determined by using the Heiskanen and Moritz formula. The Bouguer correction, including the Bullard spherical cap correction, was performed assuming an earth radius of $6,371 \mathrm{~km}$, a crustal density of 2,670 $\mathrm{kg} \mathrm{m}^{-3}$, and the Newtonian gravitational constant $6.673 \times 10^{-11} \mathrm{~m}^{3} \mathrm{~kg}^{-1} \mathrm{~s}^{-2}$. Ellipsoid height is used throughout. Outer terrain corrections were calculated to a distance of $167 \mathrm{~km}$, and inner terrain corrections were calculated to $895 \mathrm{~m}$, using $250 \mathrm{~m}$ and $10 \mathrm{~m}$ digital elevation models, respectively (Geosoft, 2010). Corpscon software (U.S. Army Corps of Engineers, 2010) and GEOID03 were used to convert from ellipsoid height to NAVD88 elevation and from geographic coordinates to projected UTM NAD83 coordinates (appendix 1).

\section{Gravity Differences over Time}

Gravity change over time provides a direct measurement of aquifer storage change (Pool and Eychaner, 1995). High-precision, relative-gravimeter measurements have been collected for this purpose in the Sierra Vista Subwatershed of the Upper San Pedro Basin. Raw measurements and tideand drift-corrected gravity differences from 2000 through 2010 are presented in appendix 2. To ensure a high level of precision, surveys done for aquifer storage-change monitoring are performed in two "loops" using the station order A-B-C-D-E-A-B-C-D-E-A. If instrument drift is not sufficiently linear, the loop may be repeated a third time. The maximum number of stations in a loop is 6 , and the maximum distance between stations is about $3 \mathrm{~km}$. Nearly all surveys have been done using the same station order within a loop and with the same gravimeter (D-209). Corrections for instrument drift and tidal effects are performed in the field during a survey using a portable computer running Microsoft Windows Mobile and Excel Mobile. The Mobile Excel file is converted to a standard excel file upon transfer to a PC and is archived in the Arizona Water Science Center gravity-data database.

In the field, average gravity values from the gravimeter analog feedback system are read at oneminute intervals and entered into the appropriate cell in the Excel Mobile worksheet. The analog feedback calibration generally is checked against the gravimeter screw calibration at least once per survey and adjusted as needed. Earth tide values for the appropriate day are preloaded in the Excel workbook, so that a tide-corrected gravity value is obtained instantly. After a station is occupied two or more times, a linear drift value is calculated, and gravity differences between each station pair are calculated by interpolating the drift rate between occupations (fig. 2). Standard deviation is calculated from multiple observations of the gravity difference between two stations. The criterion for accepting a survey is a standard deviation of $\pm 5 \mu \mathrm{Gal}$ or less between all station pairs. 


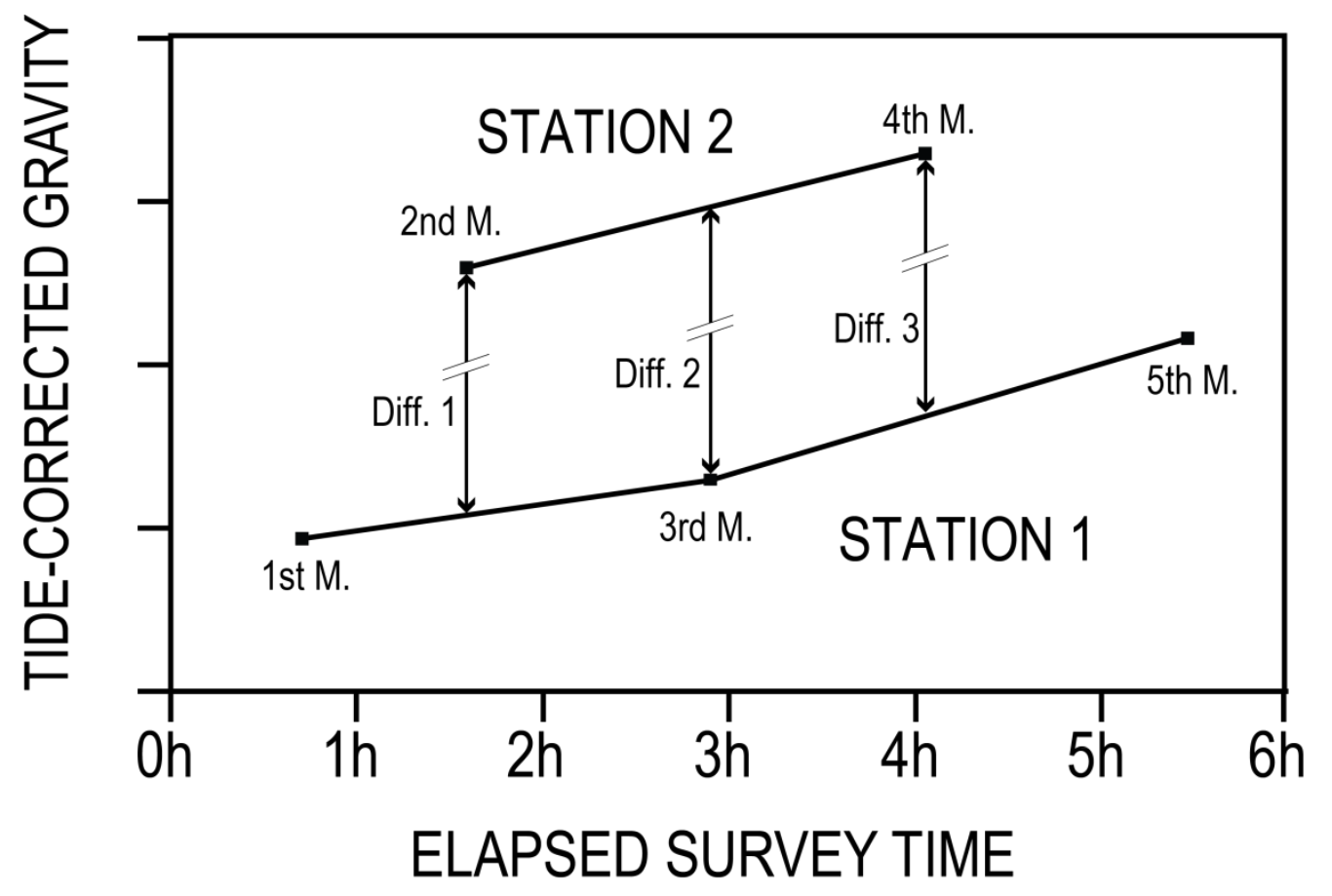

Figure 2. Method used to calculate gravity differences and standard deviation from repeat observations. (M., measurement; Diff., gravity difference)

Gravity stations for aquifer-storage monitoring are located at geodetic survey marks established by the Arizona Department of Transportation, the U.S. Army Electronic Proving Ground, Cochise County, and the USGS. These latter stations typically are constructed by encasing rebar or sectional rods, driven to refusal, within 0.4 -m-diameter concrete forms dug to $0.6 \mathrm{~m}$ depth.

\section{GPS Heights}

As indicated by repeat GPS surveys, land-surface-elevation change does not appear to be significant within the basin and no gravity correction for this effect is made. Static GPS surveys were carried out in fall 2002 and spring 2009 to evaluate ground movement as a result of subsidence or uplift at aquifer storage-change monitoring gravity stations. Continuously Operating Reference Stations (CORS) were used to determine point positions in the NAD83(CORS96) reference frame. During the 2002 survey, only a single CORS station operated by the City of Tucson, COT1, was available within $150 \mathrm{~km}$ of the project area. By 2009, the additional CORS stations COT2 (City of Tucson) and AZCO (Cochise County, located in Bisbee) had been established and are included in the network adjustment.

The 2002 survey was done using Trimble 4800 receivers in September and October 2002. GPS receivers were stationed for the duration of the survey on adjustable-height tripods at two benchmarks in the subwatershed, TW7 (Test Well 7 on Fort Huachuca) and Cochise Base (a brass cap at the Cochise County Surveyor's Office) (fig. 3). A third receiver on a $2 \mathrm{~m}$ fixed-height tripod was used to occupy each of the gravity stations at approximately one hour intervals. During the survey, high winds caused the receiver setup at TW7 to be unstable, so it was relocated to TW7A. Cochise Base was destroyed when the mark AMARILLAS was constructed at nearly the same location in 2003.

The 2009 survey was done from March 18-20, 2009. A combination of Trimble 4700, 4800, 5700, 5800, and R6 receivers were used. Receivers were stationed on adjustable-height tripods and 
tribrachs for the duration of the survey at TW7A, AMARILLAS (about 200 m southeast of AZCO), and ASA1570 (fig. 3). Three to four additional receivers, using $2 \mathrm{~m}$ fixed-height tripods, were rotated between 14 gravity stations during the survey. The survey was designed to provide maximum precision at a smaller number of stations rather than lesser precision at a greater number of stations. Trimble Business Center software was used for baseline processing and network adjustment. Precise ephemerides and a 13 degree elevation mask were used.

Final GPS positions were determined through baseline processing and network adjustment. Because of longer occupations, more receivers, and more CORS stations, point accuracies are higher for the 2009 survey than for the 2002 survey (table 1). For the 2009 survey, CORS stations COT1, COT2, and AZCO were held fixed. The positions of these stations were determined by using the published positions and Horizontal Time-Dependent Positioning (HTDP) software from the National Geodetic Survey (2009). In translating from the 2002.00 epoch published position for these positions to a 2009.22 epoch (March 20, 2009), point positions for the three CORS stations were shifted approximately 0.009 $\mathrm{m}$ north, $0.008 \mathrm{~m}$ east, and $-0.007 \mathrm{~m}$ up. Station position accuracies for the 2009 survey are between $0.010 \mathrm{~m}$ and $0.025 \mathrm{~m}$.

Only one CORS station was available for control during the 2002 survey. As noted earlier, one of the two stations where receivers were located for the duration of the survey was destroyed in 2003. To compensate for the lack of local control, the adjusted position for station TW7A from the 2009 survey was used as control for the 2002 survey. The position of TW7A was adjusted from the 2009.22 epoch to the 2002.00 epoch by using HTDP. Because of the lack of control, the network-adjusted accuracy of station positions in the 2002 survey is worse than in the 2009 survey, ranging from 0.074 to $0.454 \mathrm{~m}$. In addition, three stations (ASH, DAPALO, and H4) were positioned using only a single baseline, with an attendant decrease in accuracy.

For nearly all of the stations occupied in both the 2002 and 2009 surveys, the difference in ellipsoid height from 2002 to 2009 is within the accuracy of the GPS measurement (table 1). Height differences range from 0.193 to $-0.207 \mathrm{~m}$. Only stations FLYING and DAPALO show a height difference greater than the GPS accuracy. Furthermore, interferogram analysis of InSAR satellite images between November 2007 and April 2010 show no significant elevation change in the Subwatershed (Brian Conway, Arizona Department of Water Resources, written commun., 2010). Therefore, the height of gravity stations is assumed to be constant during the data-collection period, and no adjustments to the observed gravity values owing to height change have been made. 


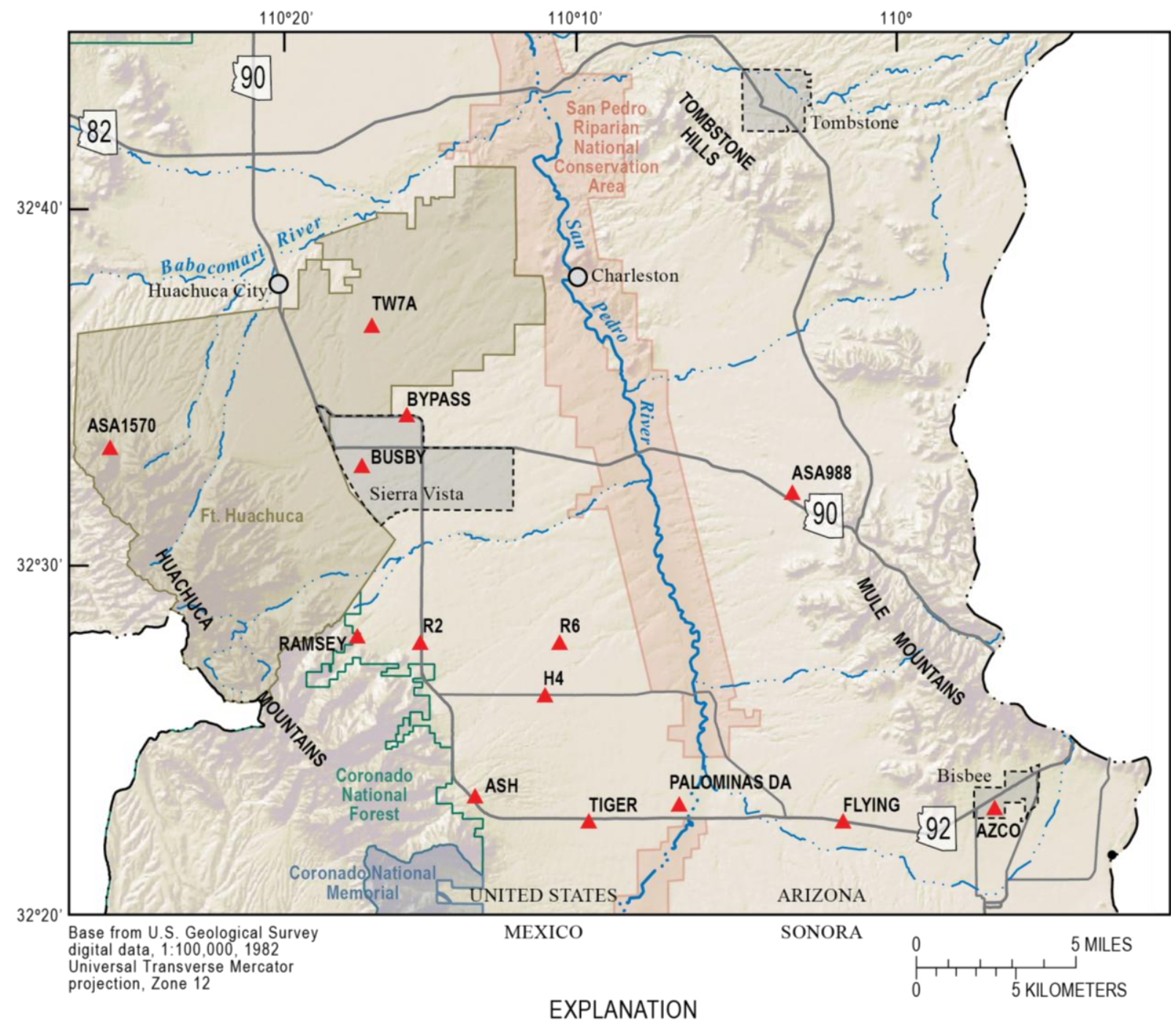

$\Delta$ GPS station

Figure 3. Map of the southern part of the study area showing GPS stations occupied in 2002 and 2009. 
Table 1. Global Positioning System (GPS) derived ellipsoid heights for selected gravity stations, San Pedro River Basin, Arizona.

[Accuracy reported at 95 percent confidence level; height is relative to GRS80 ellipsoid; NA, GPS data not available for this station; --, station height fixed during network adjustment]

\begin{tabular}{|c|c|c|c|c|c|}
\hline Station & $\begin{array}{l}2002 \text { Height, } \\
\text { in meters }\end{array}$ & $\begin{array}{c}\text { Accuracy, } \\
\text { in meters }\end{array}$ & $\begin{array}{l}2009 \text { Height, } \\
\text { in meters }\end{array}$ & $\begin{array}{c}\text { Accuracy, } \\
\text { in meters }\end{array}$ & $\begin{array}{l}\text { Difference, } \\
2009 \text { height minus } \\
2002 \text { height, } \\
\text { in meters }\end{array}$ \\
\hline ASA1570 & 1589.191 & 0.101 & 1589.067 & 0.023 & -0.124 \\
\hline ASA988 & 1338.197 & 0.159 & 1338.244 & 0.020 & 0.047 \\
\hline ASH & 1512.225 & $0.454^{1}$ & 1512.418 & 0.023 & 0.193 \\
\hline AZCO & NA & NA & 1474.166 & -- & NA \\
\hline BUSBY & 1383.176 & 0.081 & 1383.233 & 0.015 & 0.057 \\
\hline BYPASS & 1335.022 & 0.074 & 1335.037 & 0.018 & 0.015 \\
\hline COT1 & 734.116 & -- & 734.109 & -- & $-0.007^{2}$ \\
\hline COT2 & NA & NA & 759.726 & -- & NA \\
\hline FLYING & 1330.057 & 0.155 & 1329.850 & 0.018 & -0.207 \\
\hline $\mathrm{H} 4$ & 1345.589 & $0.023^{1}$ & 1345.585 & 0.017 & -0.004 \\
\hline PALOMINAS DA & 1266.637 & $0.031^{1}$ & 1266.693 & 0.020 & 0.056 \\
\hline $\mathrm{R} 2$ & 1419.617 & 0.085 & 1419.568 & 0.020 & -0.049 \\
\hline R6 & 1310.685 & 0.094 & 1310.678 & 0.016 & -0.007 \\
\hline RAMSEY & 1523.614 & 0.127 & 1523.630 & 0.025 & 0.016 \\
\hline TIGER & 1322.465 & 0.102 & 1322.442 & 0.024 & -0.023 \\
\hline TW7A & 1301.769 & -- & 1301.762 & 0.010 & $-0.007^{2}$ \\
\hline
\end{tabular}

${ }^{1}$ Station had only a single observed baseline and was not included in network adjustment. Error represents vertical precision at 95 percent confidence level for a single baseline.

Difference in height is a result of station velocity in the NAD83(CORS) datum as determined by HTDP software.

\section{Absolute-Gravity Measurements}

Absolute gravity data (appendix 3) have been collected at 26 stations (fig. 1) by using Micro-g LaCoste, Inc., free-fall absolute gravimeters. These meters use a length scale determined by a laser interferometer and a time scale determined by a rubidium oscillator. A spring mechanism isolates the interferometer from long-period seismic noise. With the FG5, about 2,400 drops are made during a 24hour period so that any residual tidal effects are effectively canceled. With the A10, about 1,000 drops are made during a 30 minute period. With both instruments, measurement sets may be removed from final processing by visual inspection if they are not consistent with other sets. Nominal accuracy is \pm 2 $\mu \mathrm{Gal}$ for the FG5 and $\pm 10 \mu \mathrm{Gal}$ for the A10. Earth tide corrections for absolute-gravity measurements are determined using the ETGTAB model with the default wave groups in the Micro-g Lacoste software. Ocean-loading corrections are determined using the FES2004 model, produced by Legos and CLS Space Oceanography Division and distributed by Aviso, with support from Cnes (http://www.aviso.oceanobs.com). Polar motion corrections were determined using coordinates provided by the U.S. Naval Observatory. The barometric pressure correction is calculated using measured barometric pressure and an admittance factor of $0.3 \mu \mathrm{Gal} / \mathrm{mBar}$.

Three absolute gravity stations were established in 2000-2001 by NGS using an FG5 absolute gravimeter and were measured twice annually between 2000 and 2007. The USGS has continued to 
make measurements at two of these sites by using an A10 portable absolute gravimeter; measurements at the third site (ASA1570) have been made at the outdoor excenter because of access issues with the original site (Note: ASA1570 was destroyed between winter 2010 and fall 2011). The remaining 23 sites were established by the USGS between 2005 and 2009, using both existing and newly built monuments. In some instances geodetic monuments established for survey control were modified to facilitate the A10 gravimeter by building a $0.5 \mathrm{~m}$ by $0.5 \mathrm{~m}$ by $0.1 \mathrm{~m}$ deep concrete pad surrounding the monument. Stations on the East Range of Fort Huachuca (HUBBARD, MW3-MW6, TW9) are located at concrete well pads. Concurrent water-level measurements made at these sites allow estimation of specific yield. At most sites, the meter is set up directly on a concrete surface; at some sites this is not possible and a short tripod is used.

Absolute gravimeters use the local vertical-gravity gradient to calculate a gravity value from observed interferometry data, and to transfer gravity values from the instrument height to the survey mark. Local gradients may differ from the free-air gradient owing to local topographic and density effects. For FG5 measurement sites and some A10 sites, gradients are measured with LaCoste and Romberg gravimeters. Surveys are between $131 \mathrm{~cm}$ height and the survey mark and between $91 \mathrm{~cm}$ and the mark. The gradient is calculated as the gravity interval divided by the height interval. Repeatable surveys are averaged at each station. Measured gradients are used at A10 measurement sites ASA1570, AAPALO, and DATOMB. At all other A10 sites, a standard $-3.0 \mu \mathrm{Gal} / \mathrm{cm}$ has been used. If the vertical gradient does not change over time, the use of a standard gradient does not cause a decrease in precision when repeat A10 measurements are compared. Gravity values in appendix 4 are reported at the respective instrument heights, corrected for setup height. All FG5 gravity values (including uncertainties) are reported at $131 \mathrm{~cm}$ over survey mark, and all A10 values are reported at $71.7 \mathrm{~cm}$, the most recent instrument height (this height varies within $1 \mathrm{~cm}$ during routine maintenance). In appendices 1 and 4, the gravity values are reported at survey mark height.

\section{Uncertainty}

The lack of an unchanging observable standard presents a fundamental challenge to assessing the accuracy of gravity instruments. Unlike instruments used to make other field measurements—such as tapes for depth-to-water measurements - gravimeters can't be calibrated against an exact metrological standard because Earth's gravitational field is changing continually in unknown ways. Nonetheless, some metrics can be used to evaluate the uncertainty in gravity measurements.

The calibration procedure for the LaCoste and Romberg relative gravimeters involves placing a series of small test masts on the beam to produce a plot of the calibration curve at different points along the screw (Valliant, 1991). Once defined, the calibration curve is scaled to gravity units by repeat observations over a $242 \mathrm{mGal}$ gravity range at Cloudcroft, New Mexico. This range is known to be too small by a few parts in 10,000 (Valliant, 1991), but this affects primarily the instrument's absolute accuracy rather than the repeatability. When using gravity data to assess aquifer-storage change, repeatability is of primary concern. Because the observed-gravity changes over time are small—less than $100 \mu \mathrm{Gal}$ (100 parts per billion) — any small error in accuracy will have an almost negligible effect on interpretation of the data. Furthermore, because the same relative gravimeter (D209) has been used for all of the repeat surveys presented here, any bias in gravimeter accuracy is constant over time. The analog feedback nulling systems on D17 and D43 used for FG5 gradients and excenter ties were calibrated by observing between nearby absolute-gravimeter sites at Table Mountain Geophysical Observatory, Longmont, Colorado.

An additional source of error in spring-based relative gravimeters is circular, or screw, error that arises from small imperfections in machining the micrometer screw that adjusts the spring (Valliant, 
1991). To minimize circular error, all repeat relative gravimeter readings are taken using an identical dial position (with the position indicator pointing to zero), at the dial setting that allows the analog feedback system to be nearest zero.

Uncertainty in relative-gravity measurements (appendix 2), as indicated by the standard deviation, is calculated from two or more measurements of the difference in gravity between stations occupied on successive survey loops. It is calculated as the measurement standard deviation, rather than the standard deviation of the mean. Therefore, it is a statistical measure of uncertainty, rather than a propagation-of-error measure based on the measurement accuracy of each individual measurement at each gravity station. The propagation-of-error method is not easily done with the analog feedback system because the output on the LCD display is fairly heavily damped, masking the high-frequency signal that is available on some other gravimeter feedback systems and is used as an indication of the uncertainty of an individual measurement. The standard deviation for a particular gravity difference presented is based on only two or three difference measurements, which cannot be considered independent because they are close together in time and use overlapping station occupations to determine a linear drift rate; it should therefore be considered an inexact estimator of uncertainty. Nonetheless, this standard deviation is useful for evaluating the relative uncertainty between different surveys.

Uncertainty in absolute-gravimeter measurements (appendix 3) arises from both instrumental and environmental sources. For the FG5, uncertainty has been determined by using both an error budget approach (Niebauer and others, 1995) and by comparing absolute-gravity measurements to the signal from a superconducting gravimeter (Van Camp and others, 2005), and generally is 1 to $2 \mu$ Gal. Summed in quadrature, instrumental sources of uncertainty for the FG5 in total are about $1.1 \mu \mathrm{Gal}$ (Niebauer and others, 1995). Instrument uncertainty for the A10 is less well known. The published accuracy from the manufacturer is $10 \mu \mathrm{Gal}$; five years of repeat observations at the USGS building in Tucson, Arizona, however, including a comparison of A10 measurements with superconducting gravimeter data over a period of 1 year, suggests that the instrument uncertainty at a quiet site is better than $5 \mu \mathrm{Gal}$.

Repeatability from observations at the 2003 International Comparison of Absolute Gravimeters for A10008 was $2.9 \pm 1.5 \mu \mathrm{Gal}$ (Schmerge and Francis, 2006). Therefore, the uncertainty reported here assumes a $5 \mu \mathrm{Gal}$ instrumental uncertainty for the A10. Even at this smaller level, A10 instrument uncertainty is by far the largest source of uncertainty and is the dominant factor in overall measurement uncertainty.

For both the FG5 and A10, an additional $0.05 \mu \mathrm{Gal}$ uncertainty is associated with the laser wavelength (which determines the falling mass position), and a $0.5 \mu \mathrm{Gal}$ uncertainty is associated with the rubidium oscillator frequency (which determines the time of free-fall). Environmental uncertainties associated with modeling Earth tides and ocean loading are about 0.1 percent and 10 percent, respectively, and uncertainties associated with barometric pressure (both measurement error and admittance-factor error) and polar motion are about $1 \mu \mathrm{Gal}$ and $0.05 \mu \mathrm{Gal}$, respectively. System setup uncertainty is estimated at $1.0 \mu \mathrm{Gal}$ for the FG5 and $3.0 \mu \mathrm{Gal}$ for the A10.

The final uncertainty source considered in absolute-gravity measurements is set scatter, which is determined from the drop-to-drop scatter of the several hundred individual drops that compose a single measurement. It is the only uncertainty component that varies between measurements, and as such, offers the best metric from which to evaluate the uncertainty of any particular measurement relative to other measurements. Drop-to-drop scatter is 40 to $200 \mu \mathrm{Gal}$ for the A10 and 20 to $80 \mu \mathrm{Gal}$ for the FG5, and primarily is affected by seismic noise. Measurement precision is determined from set scatter as (set scatter)*(number of sets $)^{-1 / 2}$. The reported uncertainty is the quadrature sum of instrumental uncertainty, environmental uncertainty, setup uncertainty, and measurement precision. 


\section{References Cited}

Dickinson, J.E., Kennedy, J.R., Pool, D.R., Cordova, J.T., Parker, J.T., Macy, J.P., and Thomas, B., 2010, Hydrogeologic framework of the middle San Pedro watershed, southeastern Arizona: U.S. Geological Survey Scientific Investigations Report 2010-5126, 36 p.

Geosoft, Inc., 2010. Oasis montaj, GM-SYS, GM-SYS 3D, and gravity and terrain correction software. Hinze, W.J., Aiken, C., Brozena, J., Coakley, B., Dater, D., Flanagan, G., Forsberg, R., Hildenbrand, T., Keller, G.R., Kellogg, J., Kucks, R., Lee, X., Mainville, A., Morin, R., Pilkington, M., Plouff, D., Ravat, D., Roman, D., Urrutia-Fucugauchi, J., Véronneau, M., Webring, M., and Winester, D., 2005, New standards for reducing gravity data-The North American gravity database: Geophysics, v. 70, no. 4, p. J25-J32.

Micro-g LaCoste, Inc., 2001, QuickTide software, http://microglacoste.com/quicktide.htm (last accessed May 2, 2011).

National Geodetic Survey, 2009. HTDP-Horizontal time dependent positioning software, http://www.ngs.noaa.gov/TOOLS/Htdp/Htdp.shtml (last accessed May 2, 2011).

Niebauer, T.M., Sasagawa, G.S., Faller, J.E., Hilt, R., and Klopping, F, 1995, A new generation of absolute gravimeters: Metrologia, v. 32, p. 159-180.

Pool, D.R., and Eychaner, J.H, 1995, Measurements of aquifer-storage change and specific yield using gravity surveys: Ground Water, v. 33, p. 425-432.

Schmerge, D., and Francis, O., 2006. Set standard deviation, repeatability, and offset of absolute gravimeter A10-008: Metrologia, v. 43, p. 414-418.

U.S. Army Corps of Engineers, 2010. Corpscon Version 6.0, http://crunch.tec.army.mil/software/corpscon/corpscon.html (last accessed May 2, 2011).

Valliant, H.D., 1991, Gravity meter calibration at LaCoste and Romberg: Geophysics, v. 56, no. 5, p. 705-711.

Van Camp, M., Williams, S.D.P., and Francis, O., 2005, Uncertainty of absolute gravity measurements: Journal of Geophysical Research, v. 110, B05406. 